Article

\title{
Objective Structures and Symbolic Violence in the Immigrant Family and School Relationships: Study of Two Cases in Chile
}

\section{Rayen Cornejo Torres * and Ariel Rosales Ubeda}

School of Social Work, Pontificia Universidad Católica de Chile, Santiago 781000, Chile;

E-Mail: aarosale@uc.cl

* Author to whom correspondence should be addressed; E-Mail: rcornej1@uc.cl;

Tel.: +56-9823-7474.

Academic Editors: Nathan Hughes and Martin J. Bull

Received: 28 October 2015 / Accepted: 26 November 2015 / Published: 4 December 2015

\begin{abstract}
The historical trend of migration processes in Chile faces a challenge given the incremental growth of immigration during recent years. This study focuses on the relationship between family and school, distinguishing within it the particular relationship between immigrant families and school agents. The qualitative approach applied here enabled a focus on the effect of the cultural diversity that immigration produces, including the configuration of conflicts between immigrant families and the school institution. The main issues discussed in this article concern the approach and the nature of interaction between schools and immigrant families. This approach is articulated with the observed emergence of symbolic violence. The characterization of the conflict of expectations among immigrant families and schools is also described, suggesting the need to rethink the practices associated with an inclusive education that allows the integration of immigrant families.
\end{abstract}

Keywords: education; immigrant families; conflict

\section{Introduction}

This study focuses on the relationship between family and school, distinguishing within it the particular relationship between immigrant families and school agents in Chile. Immigration has become a public problem in Chile, and a relevant issue in Latin America. According to the World 
Bank [1] there are more than 215 million international migrants ${ }^{1}$ worldwide. The 2011 study "Migration and Remittances" from the World Bank shows figures that help understand the context of international migration. The information presented by this study shows that more than 215 million people (3.0\% of the world population) live outside their countries of origin, a figure that has increased from the 191 million people in 2005 [2], but has decreased since 2011.

The main destinations of migration flows are the developed countries. The World Bank notes that the first migration destination is the United States (US) [1]. Nevertheless, between 2005 and 2010, there has been a surge in flows of immigrants into the United Kingdom (UK), mainly from Eastern Europe, as well as from Latin America and North Africa [1].

Latin American and Caribbean migrants represent an important percentage of the international migratory movement. The Comisión Económica para América Latina y el Caribe (CEPAL) estimated that there are about 28 million Latin Americans and Caribbeans living outside their home countries [3]. The volume of migration among developing countries has increased over the last decade and is relatively higher than the Latin migration to high-income countries belonging to the Organization for Economic Co-Operation and Development (OECD). During the last decades Chile has increased heavily the numbers of immigrants arriving at our land.

During recent years, social diversity and cultural heterogeneity in Chile have increased [4]. Among the several phenomena that have strongly influenced the growing differentiation of the population, immigration has become key. The cultural diversity that accompanies immigration renders, in turn, the delivery of social services difficult.

The education system is a realm where several social agents interact, and it is organized mainly as a result of rules agreed on and regulated by the state. Within this social field different participants' expectations and dispositions meet, including those of students, families, school administrators, and teachers [5]. While there may be a high degree of functional harmony, this may also induce conflict. Each agent perceives, thinks, and acts differently, provoking disagreement and conflict. The various dispositions among these agents do not necessarily support each other, nor are they necessarily in agreement with the rules of the education system. This produces incompatibilities, discrimination, and violence in several directions, and this is what this article makes visible.

On top of these aforementioned challenges, immigrant families endure many difficulties affecting social integration, which may obstruct the learning process of their children [6]. The problems faced by families are diverse and with distinct complexities; these are associated with dispositions influenced by the size of a series of capitals — cultural, social, economic - giving support to the meaning of their practices.

On the other hand, the homogenous character of frameworks and demands of Chilean policy results in a lack of ability to fully and properly deal with the existing cultural diversity in educational institutions with high degrees of immigrant populations [7]. This obstructs the learning processes and affects the way students - and families - from external cultures integrate in the educational system.

Even though advances in coverage and quality of education are credited to the Chilean educational system, several challenges persist; one of these is associated with the recognition of social diversity in

1 According to the International Office of Migration (2011), some of the reasons for international migration are the following: the political transition in North Africa and the Middle East in 2011, increased natural disasters and displaced people, increased armed conflict, and economic crises in developing countries. 
the educational processes and strategies. Thus, there are some deficiencies associated with the appreciation of alternative points of view of both indigenous people as well as immigrants who have become part of the national population.

In Chile, the immigrant population continues to increase steadily [4,8,9], and schools and immigration-related institutions cannot merely neglect a new multicultural reality in the classroom. Hence, students from different corners of Latin America, along with their families, get incorporated as new actors in this social field.

In 2010, the Departamento de Extranjería y Migración (Department of Foreigners and Migration) [9] calculated proximally the presence of 352,000 foreign people in Chile. This figure corresponded to about $2 \%$ of the total population. This presented an important increase with respect to the census of 2002 [10]. In addition, $73 \%$ of the foreign residents in Chile corresponded to people from South America [9]. It showed an important contrast compared with the profile of immigration between the 19th and the first half of the 20th centuries, consisting mainly of people coming from Europe [4,10,11].

The new profile of immigrants has acquired more visibility, giving a new meaning to the migration process $[4,12]$. There is currently a cultural dichotomy about appreciation/rejection. On the one hand, European immigration is considered positive for national development [4,12]. On the other hand, the arrival of Latin American immigrants is seen as harmful because they are stigmatized as delinquent, poor, and inferior to non-immigrants [4]. This situation has contributed to the perception that the current migratory movement is a social problem [13].

There are different causes for immigration from South America depending on the countries of origin. The immigrants from Argentina tend to arrive for familial reasons, while the people from Peru, Ecuador, and Bolivia seek employment $[9,10]$. In this last group, there is a predominance of females seeking work in domestic services. The latter has been labeled as "the feminization of migration" $[4,10,11,14]$.

According to Tijoux [15], one of the most important effects of this phenomenon is the increase of familial reunifications. This brings new difficulties to family life, since these newly arrived children lack the support of their extended families. Not unusually, these children are left alone, are taken care of by the neighbors, or stay simply locked inside. These situations influence the child's socialization [15].

Additionally, the cost of life in Chile and the difficulties in finding formal employment imply the danger of labor exploitation, of living in poor accommodation, and of experiencing discrimination. This context facilitates physical and psychological abuses of immigrant children, which negatively affects their emotional stability [16].

The international migratory movement has forced the reformulation program in various public services in recipient countries, as in the case of education in Chile.

Concerning education, Chile signed the International Covenant on Economic, Social and Cultural Rights. It recognizes the right of education for every child, whether Chilean or foreign [15]. Regardless of whether immigrant children have Chilean documentation or not, admission to the education system must be granted for all children.

According to OECD data, inclusion of immigrant students in Chile accounts for the $1 \%$ of total enrollment, similar to the rate of countries like Brazil, Colombia, Peru, Turkey, Hungary, and Thailand [8]. Various studies [7,8] indicate that the presence of immigrant students in the Chilean education

2 According to Martinez (2003) one of the effect of the femenization of migration is family reunification, among others. 
system is mainly influenced by the socio-economic and employment situation from both families and countries of origin ${ }^{3}$.

While the distribution of students (first and second generation) from foreign origin is given throughout the country, it concentrates in the regions of Tarapaca, Antofagasta, and mainly in the metropolitan area, which has more than $60 \%$ of the immigrant population. Within this region, establishments with a high percentage of immigrant students are mostly in the areas of Santiago, Independencia, Estacion Central, and Recoleta.

Data on cultural heterogeneity of the Chilean education system indicate that 4711 of 12,063 (39\%) registered establishments in 2011 had immigrant students, while over 6000 establishments did not register any. The numbers indicate that, on average, there are about seven immigrant students per establishment. In schools with enrollment of foreign students the dispersion varies between $2 \%$ and $100 \%^{4}$; in other words, there are institutions with very low immigrant populations and others where all students are children of immigrants [8].

The growing presence of foreign students in the Chilean education system has led the state to take action to promote the integration of immigrant students in schools through various initiatives. One of them is the "right to education for children and young migrants" program, which focuses on the student and downplays the importance of the relationship between schools and families in the educational development of students.

Therefore, immigration and school play a relevant role favoring integration and inclusion. In this article, the family-school conflict is analyzed in the context of a high foreign population within Chile's education system ${ }^{5}$. The study illustrates the described conflict by presenting three issues of particular importance. First, the aspects obstructing the interaction between families and schools are described. Second, differences in expectations constituting the basis of the conflict are considered. Finally, the establishment of the symbolic violence operating in this relationship is exposed.

Chile has not developed studies on the family-school relationship in the context of the migrant population. In this scenario, this study has a double significance. On one hand, it provides theoretical information about how the links between families and schools are presented in contexts of high migration, adding cultural diversity, something that has not been done so far in national studies. On the other hand, findings contribute to the development of cultural integration initiatives in education, by questioning the dynamic between actors and guiding the proposal designs to improve intercultural understanding in the relationship.

3 This article considers immigrants and children of immigrants born in Chile as a unit of analysis.

4 The data does not reveal if students are immigrants of first or second generation. In Chile there are only three schools with $100 \%$ foreign registration.

5 Chile's school system is complex and diverse in terms of its administration. It is characterized by a decentralized organization, meaning that its management is performed by municipal institutions, private individuals, and foundations (privates backed with state subsidies), who take the duty of providing education and keeping schools working. In this context, Chile's educational system has three types of schools: public (state-owned), fully private, and subsidized private schools. Along with this, the Ley Orgánica Constitucional de Educación (1990) guarantees the right of the education centers to elaborate on and apply their own teaching programs in an autonomous and non-centralized way. This legal entity ensures everyone the right to education from infant schools on, and establishes teaching liberty as the guiding principle of politics and educational organization in the country. 


\section{Methodological Aspects}

\subsection{Aims}

The general aim of this article is to analyze, from a Bourdieuninan perspective, the conflict between family and school in a context of a high immigrant population. The characterization of the conflict, regarding different expectations in families and in schools, is performed using the theoretical perspective of Pierre Bourdieu [17] in order to qualitatively analyze the results of an empirical study in two schools in Santiago de Chile serving a relevant population of international immigrants.

Specific aims are:

(1) To characterize the main difficulties immigrant families faced during their process of integration into the socio-educative realm;

(2) To define the facets of the conflict between family and school;

(3) To explore the presence of symbolic violence in this relationship.

\subsection{Study Design and Sampling}

This is a qualitative study that explores the relationship between families and elementary schools in high-immigration areas in Santiago de Chile. This is exploratory research due to the lack of previous research in this area.

The selection of schools has non-random criteria, associated with the high number of immigrants present in each school. It stands out that, at a national level, there are two schools with the largest number of foreign students.

One of the schools, known in the study as RA, has received immigrant students since 2000 and has been considered a pioneer countrywide in teaching foreign students. Currently, this school implements its own educational project. The other school, known as ULA, has received foreign students for the last five years, and is still developing its educational project.

A convenience sampling was used ${ }^{6}$, hence the selected schools - serving both international migrants and Chilean students - are not representative of the Chilean school system as a whole. In summary, this non-random exploratory study does not guarantee the representativeness of the sample and, therefore, the results cannot be generalized. Nevertheless, the schools being studied receive the largest immigrant populations; therefore important practice developments can be highlighted from these two key institutions.

Inside of these schools the key informants for the study were chosen according to their degree of representativeness among the various actors involved in the educational community. In this way, this study incorporates the views of professional school workers such as teachers, social workers, psychologists, and school managers, who had worked in the school for at least one year. On the other hand, different kinds of families whose children attended the schools were also represented in this study. The sample includes immigrant parents (mainly from Peru, Ecuador, Colombia, Haiti) as well as Chilean parents because both are in the educational community and have their own views regarding the other families and the relationship with the school. The sample also included groups of parents with

6 This type of sampling selects research units that meet the requirements of the population under study, but nevertheless, they are not selected randomly. It is preferably used in exploratory studies. The pilot tests also often use this type of sampling. 
different levels of participation in the school (for example, some visited the activities organized by the institutions regularly and others only seldom), and the families, therein, were selected by recommendation from the school personnel, keeping in mind the above criterion of diversity. As a prerequisite, the children of these families must have attended the respective school for at least six months.

\subsection{Data Collection}

The data collection took place between March 2012 and July 2013 and included 38 interviews. These interviews were performed inside the schools, as a face-to-face conversation between the researcher and the parent. The average time of such a conversation was 50 minutes. There were two sets of questions: one for the parents, concerning their view of the school, their relationship with it and with other families - including nationals and immigrant families - and their family life, and another for the school team, regarding their role in the school and their relationship with families and immigrant families. In each instance, anonymity and confidentiality were ensured and informed consent was obtained. Interviews were transcribed verbatim. Fieldwork was finalized when the information obtained reached "saturation" along the triangulation by itinerancy of data [18].

Alongside the fieldwork, a literature review of academic research was undertaken, principally regarding Bourdieu's work [5,17,19-22], as well as research about immigration in Chile and education [4,6-10,15].

\subsection{Analysis and General Discussion about Pierre Bourdieu}

In this article, a thematic analysis approach based on Bourdieu's perspective is adopted, and with this, the preliminary categories are developed (see the end of this section). This method identifies themes or patterns within the data [23]. All the information was codified according to the preliminary categories identified from the literature, with new categories subsequently developed from the data.

Pierre Bourdieu's theoretical perspective examines social order, and postulates that in order to do so, it is necessary to reject, as a sole possibility, both the structuralist point of view, according to which structures reproduce with the forced participation of agents under coercion, and the interactionist or ethno-methodological perspective, according to which the social world is a product of the actions of creation that, moment after moment, the actors perform [19]. For the author the answer lies in the articulation of both theoretical perspectives.

The social world implies a dual existence. It finds itself imbedded in an internal dynamism, which simultaneously includes objective structures — objects, institutions, etc. - as well as subjective structures associated with the agents' dispositions. Every society rests over the relationship of two dynamic principles: one is the objective structures, referring to the distribution of capitals - cultural, economic, social, symbolic, etc. - as well as the mechanisms guaranteeing its reproduction; and the other is in the subjective representations of the agents. The relationship between these two principles tends to organize the social forms and the reproduction strategies that accompany them (see Table 1). 
Table 1. Definitions and expressions of capital according to Bourdieu.

\begin{tabular}{ll}
\hline Type of Capital & Definition \\
\hline Economic & $\begin{array}{l}\text { Control over economic resources. This type of capital can be converted into money, } \\
\text { and is an essential source of political power and hegemony [21]. }\end{array}$ \\
\hline Social & $\begin{array}{l}\text { Typically, intangible resources based on the membership to a group, relationships, } \\
\text { influence, and collaboration networks [21]. }\end{array}$ \\
\hline Cultural (institutionalized) & $\begin{array}{l}\text { The categories of knowledge, education, skills, and advantages that a person has and } \\
\text { that give him/her a higher status within society. In principle, parents provide their } \\
\text { children a certain cultural capital, transmitting them attitudes and knowledge } \\
\text { necessary to develop in the current educational system [21]. }\end{array}$ \\
\hline Consists in a series of intangible properties inherent to the subject, which may \\
uniquely exist as long as they are recognized by the rest. It can only be attained after \\
acquiring the other capitals [21].
\end{tabular}

From such principles Bourdieu [21] defines society as a social space structured by the relationship between objective structures (capitals) and subjective (habitus) ones at the agents' disposal (among them the family). This structuralization transfers to different fields which compose the social world. Each field is relatively autonomous in its functioning; hence, each of them fixes their own rules to protect themselves from the heteronomic influences of the other ones [22,24]. From this point of view, there are different social fields coexisting in the social space whose limits are given according to their effectiveness to influence and implement rules that regulate the social relations of the agents.

Bourdieu [21] remarks that a "social field" is a space of action where agents interact and conflictive social relationships are established as a product of the differences between the dispositions of each of them. Social practices are based on regularities associated with a socially structured environment producing habitus [21]. Thus, habitus constitutes itself into the main generating principle of the social practices.

For Bourdieu, habitus $^{7}$ is the set of generative schemes from which the agents perceive the world and act in it. These schemes are socially structured, meaning that they have been conformed to throughout the history of each agent and suppose the internalization of the social structure, the concrete field of the social relationships in which the social agent has conformed to as such. However, at the same time, they are structuring; they are the structures from which thoughts, perceptions, and agents' actions are produced [25].

The constitutive dispositions of the habitus - inculcated in a lasting way by the objective conditions and by a pedagogical action that tends to adjust to those conditions - are prone to engender expectations and practices objectively compatible with such conditions and are adapted ex ante to their objective requirements; put differently, by being a product of certain types of objective regularities, these general and transferable dispositions therefore tend to engender all "reasonable" practices which are possible within these limits, and only in their setting.

7 The habitus is a system of different types of dispositions which enjoys a certain volume of expanded or diminished dispositions and a trajectory of acquisitions in time, making the agents have the capacity to generate practices and representations in the fields since these dispositions are engendered in their experience. Thus, the practices are meaningful and they are reasonable [19]. 
The theoretical core of Bourdieu's perspective maintains that social relationships are the result of the internalization of a set of cultural practices and social appreciations which are perceived as "normal" by the agents that experience them and which condition their social practices [19]. Related to this, Karen O'Reilly [26] approaches the migration phenomenon from the theoretic perspective of Bourdieu, specifically emphasizing how the habitus explains the internalized schemes of the social agents, since these vary with the migratory practice. There are also other perspectives interested in the migration phenomenon from Bourdieu's perspective that emphasize the notion of habitus as well ${ }^{8}$. This means that despite the differences in power, wealth, and a series of other resources and capitals, the ascribed and the incorporated habitus ${ }^{9}$ in the agents signals the trajectory and at the same time structures their axiological dispositions. In other words, the resources and activities of human capital (education), social capital (information, contacts, influences, networks), and cultural capital (values and behavior styles), among others, at the disposal of people and homes, allow them to improve or maintain their social insertion and/or reduce or reproduce their social vulnerability.

This shows that beyond the economic differences, in society, there are other distinctions separating the agents depending on the social environment and differentiation factors that are internalized and reproduced by the agents in various fields. Everyone adopts habits, behavioral ways, and attitudes of their original social environment, inheriting differentiated know-how and tastes whose profitability achieves to be differentially efficient in time within the social space. This means that every interaction has a cultural reference point and refers basically to a "way of life" shared by the people of the same original culture in given historical and societal contexts.

According to this view, it is assumed that social differences are not exclusively related to economic capital, since the latter is not the only one structuring social divisions, as classical Marxism would have it. There are other forms of capital — cultural, social, symbolic, political, bodily [19] —incorporated in the discussion around social distinction, which are structuring factors of the distinction. Along this line, the structuration of strata and social classes is nothing more than the product of the degree of existence of the different types of capital. This is to say that the ranking between the more and less privileged is a function of the distribution of the several capitals and their use in different fields of the social space; the differentiated position of the agents and social groups in the structured social space depends on the volume and capital structure.

Among the mentioned types of capital, [19] Bourdieu gives more importance to cultural capital because of its influence and profitability. The author remarks that this capital is acquired by multiple socialization instances, the more permanent and outstanding ones among them being family, education, and pedagogical work in the school. In turn, the author notices that pedagogical work in schools will

8 For example, Pintor [27] develops a reasoning based on transnational habitus, pointing out how the effects of migration transform the lifestyles of the migrating subjects, their society of origin, and their host society, since migrants may live simultaneously in both of them.

9 The habitus is understood as a set of rules incorporated with personality, guiding choice, lifestyles, abilities, etc., which in the end generates social distinctions. The individuals resulting from the socialization process learn to behave, relate, and think in a specific way, and therefore, individuals get used to living under a certain expectation horizon, which is always conditioned by the horizon formed by the possibilities of action, which is composed by the degree of the different capitals possessed by the agents. It is through their habitus that the agents incorporate into their lives the usual practices that become normal and transform them into dispositions of their practices. 
have a differential productivity in the learners according to their social class of origin, depending on the material conditions of their existence. Hence, whenever there is a noticeable cultural distance between the habitus at the beginning of the student (natural) and the pedagogic contents to be taught, under the goal of efficiency, the pedagogical relationship must be arbitrarily imposed to vanquish the resistance exercised by the natural habitus, such as of the pupils of foreign roots.

The importance of the capitals - inherited or acquired - in praxis lies in that the agents and the social groups pursue strategies ${ }^{10}$ according to the volume and capital structure they possess, which is dependent on the position they occupy in the social space and the capacity to operate in diverse fields of action. Such strategies are oriented toward transforming or preserving the distribution structure of the capitals in society and in the different fields comprising it. The strategies, therefore, have the intention to improve or maintain social position and the situation of the agents within a particular field or within a total social space. In the end, strategies generate a sort of adaptation to social situations, and consequently have a producing and reproducing result.

In the development of the concept of cultural capital ${ }^{11}$, Bourdieu enables the introduction of the cultural variable in the context of educational research. In this regard, it has been empirically shown that schools play an increasingly important role in the transmission of the advantage through generations. In this line, Lareau [28] notes that different social classes defer in how parents see the happiness and success of their children. According to Lareau [28], middle-class parents actively promote the talents, opinions, and skills of children, which can be called "concerted cultivation". Some of the practices associated with this strategy are: enrolling children in organized activities, reasoning with children (answer questions with questions), and closely monitoring the experiences of children in institutions such as schools. Through this pattern of concerted cultivation, middle-class children gain an emerging sense of entitlement.

Additionally, Bourdieu's sociology [19] of education stands from the theory of symbolic violence and the general theory of social reproduction. For Bourdieu, every teaching, in school or at home, relies on authority and, hence, refers to relations of power. Here is where the concept of "symbolic violence" appears, which is seen as an imposition of systems of symbols and meanings over groups or classes, impositions that are regarded as legitimate within a functioning structure.

Keeping in mind that every culture has its own arbitrariness, coming from the socialization process, the educational system has its own cultural arbitrariness, which is that of the dominating classes. For this reason, the pedagogical action also reproduces the relationships of power by reproducing culture.

In particular, Bourdieu [21] considered that disposition toward culture, the institutionalized cultural capital, was rather a result of family education and the recognition of the importance given to education and inheritance. On the other hand, for Bourdieu, those who possess the political and

10 Bourdieu remarks that in practice, strategies are varied, interdependent, and appear intertwined. Nevertheless, it is possible to classify and categorize them analytically. The author mentions the existence of strategies of type: biological investment, economic investment, couple-related, and symbolic investment, among others. These types of strategies, beyond supposing a rational and strategic behavior of the agents and social groups, express the habitus and the volume of capital present in them.

11 A dominant interpretation of cultural capital has teamed up with two key premises. First, the cultural capital with ease denotes knowledge or aesthetic culture, known as "cultured". Second, the cultural capital is analytical and causally distinct from other important forms of knowledge or competence (called "technical skills", "human capital", etc.). 
economic capital dominate over those who possess the cultural capital, which is the principal means of cultural reproduction. Symbolic systems are doubly determined by the pressures derived by the intellectual field on one side and the class field on the other, whose interests are expressed in the form and content of the symbolic power $[22,23]$.

From this theoretical perspective, the present article deconstructs the relationships between families, immigrants, and the school, exploring key points concerning the conflicts between these social agents. Put otherwise, this proposal allows us to objectivize the social relationships in the educational field in that it renders visible subjective-objective aspects and ways of thought and action of both families and the school. The following section describes the process of data analysis based on the collected empirical data and the described theoretical framework.

The analysis is structured as follows: in Section 3, we discuss the difficulties of the migrant families in the social-educational field; in Section 4, the dimensions of the family-school conflict are described; and in Section 5, the structuring of symbolic violence in the educational field, assimilation and domination, is expanded on. Lastly, in Section 6, the final conclusions are presented.

\section{Difficulties of Immigrant Families in the Socio-Educational Field}

An understanding of the conflict between schools and families requires a description of immigrant families, as well as the way it becomes an agent transmitting the habitus originated in the country of origin. The following section provides this.

The observations gathered through fieldwork showed that families presented diverse structures, usually associated with matriarchal single-parent and two-parent categories (See Table 2). These types relate, on the one hand, to the process of migration endured by the families, and, on the other, to family disintegration as a result of problems related to one of the parents with justice or through break-up.

Table 2. Types of usual families observed.

\begin{tabular}{ll}
\hline Types of Families & Description \\
\hline \multirow{2}{*}{ Matriarchal single-parent } & $\begin{array}{l}\text { Families where the head of the household is a woman and there is no male } \\
\text { paternal figure in the conjugal system }\end{array}$ \\
Two-parent & Families that are composed of paternal figures, male and female \\
\hline
\end{tabular}

From a theoretical point of view [19], families provide the tools for the students to interact with a larger context. This transference depends on the capitals the families have, since they allow them and the pupils to get used to diverse social fields. Prominent among these social fields are the economic capital, the social capital, the symbolic capital, and, fundamentally, the cultural capital, since it is through this one that some strategies that maximize the learning of immigrant students are transmitted.

There are different difficulties in terms of family capitals (see Table 3). In a relational plane, family disintegration and the loss of networks implied by moving away from home reduce migrant families' social capital. In addition, the difficulty in adapting and the social segregation endured by most families make it harder to access new networks for childcare when parents work most days. 
Table 3. Difficulties in terms of family capitals.

\begin{tabular}{|c|c|c|}
\hline Type of Capital & Structure & Volume \\
\hline Economic & $\begin{array}{l}\text { Development of activities of low } \\
\text { qualification and long workday. }\end{array}$ & Low and unstable income generation. \\
\hline Social & $\begin{array}{l}\text { Break of social and family relationships as a } \\
\text { result of migration. }\end{array}$ & Low support networks for childcare. \\
\hline Cultural (institutionalized) & $\begin{array}{l}\text { Low and medium level of studies } \\
\text { (scholarship) of the parents. }\end{array}$ & $\begin{array}{l}\text { Limited knowledge for learning support } \\
\text { to their children. }\end{array}$ \\
\hline Symbolic & $\begin{array}{l}\text { Recognition and empathy for the situation } \\
\text { of the families. }\end{array}$ & $\begin{array}{l}\text { Discrimination and abuse of power that } \\
\text { school exerts against families, and } \\
\text { national families against immigrant ones. }\end{array}$ \\
\hline
\end{tabular}

On the other hand, the educational level of the parents that participated in the monitored schools was relatively low, except for a few cases where the parents had professional degrees. Immigrant families, therefore, presented a low level of institutionalized cultural capital, which, as a result, curtails the capacity of parents to help their children with homework and other study-related activities.

The low level of institutionalized cultural capital of the migrant families deteriorates their supporting capacity which, in turn, could make the acquisition of academic support allowing the development of competence to better cope with other social fields harder. This difference between volumes of cultural capital is detected both by the families as well as by the school agents; the following sentences exemplify it:

"The child does not advance because behind him there is no support to do the homework, no support, no encouragement; for example, a little child could have a lot of problems, but whether the mother is there or not, the child is always going to try something. But these children do not perform and the mother neither. It is like nothing." [29].

"Not everyone has the same social class, but more than social class I would say it is a problem of education. They do not come with the same educational level to Chile. We have mothers that have arrived as total illiterates and others that came with university studies almost finished. And of course we can see the difference. Then I would say that more than the economic part it is the educational level [that matters]. The higher the educational level, the more the parents take care. The lower the educational level, the lower the value of education, and the higher abandonment of the parent." [30].

On the other hand, in the economic realm, it is observed that the adults of the migrant families generally undertake activities requiring lower qualifications and long working days. The first point translates into low remunerations, while the second one influences the direct relationship with the school in the sense that the parents do not have enough time, as required by schools, for meetings and other formal activities.

"Those who work cannot have a lot of time like those who do not work. Because I work, I must meet schedules. Then, I come, I pick up him and I leave him. But suddenly I cannot pick him up because of my job schedule. Then when I have one moment with the teacher, it could be in the morning for a little time for talking, and after, I leave very fast. It is less 
than the times for mothers that are not working. For example, now I am with postnatal leave period (protected nonworking time in Chile), I come and stay more time speaking with the teachers." [31].

"There has been a lot of absenteeism by the parents, and there are few parents that do come. Maybe not because they do not want, but the work precludes it. I try to come when possible.” [32].

"But as a foreigner, I cannot...and I want that the people to be conscious, whether they tell me 'there is a meeting on such day'...I cannot, because if I request permission at work, and they do not give it to me. Neither, I cannot miss going to my work, because I would lose it. For this people must be conscious, because there are days with permission and others without permission." [33].

The socioeconomic level - identified by the accumulation of cultural capital-appears as a differentiating condition in the educational process. To schools, it influences the capacity of parents to support their children, and the promotion of education. A positive association is observed between economic capital and cultural capital, indicating that the higher the socioeconomic stratum, the more positive the valuation of education.

"I think that also depends on the socio-economical level of the immigrant person. Because when they have higher socioeconomic level, the immigrant people have other perspectives. But when they are from those little towns and rural areas, they do not have those perspectives. But in general, for the children here, we want that they go study to secondary school at least." [34].

Considering the previous context, there are some conditions obstructing the participation of immigrant students in the Chilean education system. Among these, socio-cultural and economic factors of the families are recognizable as elements that depend on the way they are manifested could make a student's integration in his/her new educational context harder.

\section{Dimensions of the Family-School Conflict}

The educational system is a social field of fundamental importance for the socialization and transference of culture. By means of education, distinctions are created which make possible the production and reproduction of the social structure. At the same time, dispositions in the guise of cultural capital that serve as input for the practices of the agents in other social fields are produced.

Specifically, in the educational field, the school has become an important point of welcoming, meeting, and interaction in those societies/countries receiving migrant populations. Immigrants and locals must interact on a human scale inside this specific social field. In this section, we present some aspects underlying the conflict in expectations between the social agents (see Table 4), both immigrant and local families and schools, inside the observed socio-educational field.

It was noticed from the observations in the field that the conflict between families and schools touches on three fundamental aspects: a struggle of interests, the different dispositions toward action, and the divergence in expectations among the agents. 
Table 4. Aspects associated with the conflict between the school and immigrant families.

\begin{tabular}{|c|c|c|}
\hline & Category & Code \\
\hline \multirow{3}{*}{ Conflict } & $\begin{array}{l}\text { Struggle of interests: Refers to differences } \\
\text { in the assessment of teaching and } \\
\text { educational space. }\end{array}$ & $\begin{array}{l}\text { - } \quad \text { Value of education: low to high } \\
\text { - } \quad \text { Support for the educational process: real, apparent, null } \\
\text { - } \quad \text { Role of school: protector } v s . \text { educator }\end{array}$ \\
\hline & $\begin{array}{l}\text { Difference of dispositions: Refers to the } \\
\text { practical sense in the educational field. It } \\
\text { has to do with the different predispositions } \\
\text { shown by families in the educational social } \\
\text { field from their experience. }\end{array}$ & $\begin{array}{l}\text { - Practical history: negative or positive } \\
\text { - Adaptability: pro to unfavorable } \\
\text { - Provisions: high or low expectations, indifference }\end{array}$ \\
\hline & $\begin{array}{l}\text { Mismatch of expectations: Refers to } \\
\text { differences between expectations in } \\
\text { a given situation. }\end{array}$ & $\begin{array}{l}\text { - } \quad \text { Participation in educational activities } \\
\text { - } \quad \text { Relationship school-families } \\
\text { - } \quad \text { Purpose of education } \\
\text { - } \\
\text { - }\end{array}$ \\
\hline
\end{tabular}

In the first instance, the interests of each agent come into conflict because of the logic they found in teaching and the educational space. With respect to the interests shown by the interviewed families, migrant and Chilean, regarding the education of their offspring, it was possible to tag three lines of argumentation.

For a first group of families, school has a specifically protective role. They see in it a place for their children to be safe as adults work, and there is not much more value assigned to whatever else school may mean for their future. In this group there are families that simply take their children to school in order to avoid legal issues, since in Chile it is obligatory for children of schooling age to attend schools.

"I think that the priorities are a little untidy, because the realities are very different with our opinion about what must be. Here there is a great number of parents that send their children because they must send them. Because otherwise someone is going to complain. Because otherwise, the children can fall in SENAME, because the law requires it." [35].

A second group of families say that school is important for their children, yet in reality they do not support the educational process of their offspring. Here the application of a certain well-intended discourse can be observed, which, however, does not translate into a transformation of the dispositions of families, since there is no actual positive valuation of education. Put otherwise, in these families, there is a difference between their discourse on education and the practices of educational support.

"They want their children to study. But one thing is that I want them to study, and other is what are my action to stimulate that." [36].

A third group of families value education, since they see in it better chances for the future of their children, which consolidates school as an important agent for their future well-being. These families, the difficulties in finding time to participate in the educational process of their children notwithstanding, seek ways/strategies in order to be present and not to miss informational and educational instances given and required by the school. 
"It is a minor group that have the conviction that children need education, that they can opt to study, pursue a career, be a man or woman of good." [35].

Accordingly, this group is the one demanding schools provide more support, activities, and effective learning for students.

The school, in turn, imagines itself as performing a role fundamentally as educator, and sees education as a highly valuable input for the development of the children in other fields in the future. Thus, differences in the directions of conflicts were observed, since, on the one hand, for the school, it is problematic that the first and second groups do not respond effectively to their required role in the learning process. On the other hand, for the third group, it is a point of tension that schools do not respond to their demanding more participation and/or excellence. Key factors are the value of education and the role of the school.

Another issue related to the conflict between families and schools is in the difference of perceived dispositions by means of the practical sense of the agents in the educational field. This is related to the previous experience of the family groups and their trajectory in this field. Here it is observed that experience in the educational system predisposes families when facing schools and, at the same time, educational agents working for the school to be conditioned by their regular practices. This conditioning results in operating in ways not necessarily in tune with what families expect for the education of their children.

Therefore, the practical sense incorporated in the agents of the socio-educational field generates expectations on the agents and predisposes families to face a school's demands. According to the observations, the trajectory of family practices in the educational system generates two types of predispositions for insertion in schools. Basically, a good previous experience, associated with a positive relationship with the school and satisfaction with respect to the contents transmitted to the child, increases the value of education and, at the same time, generates high expectations regarding the educational process. This, in turn, favors the adaptation process of the children and the families to schools, whereas a less demanding experience — of lower value - makes insertion more difficult, which refers to negative or neutral predispositions with respect to the educational process.

The differences between the observed expectations point to the third dimension characterizing the family-school conflict (see Table 5). In it, the arrival of the immigrant families is key since it refers to the appearance of new social actors in the educational field, which generates new demands and interests that have an impact on the relationships in this system. The insertion of immigrant families in the educational space implies some variation in the social relationships associated with the teaching processes normalized in the school.

The immigrants, as agents, generate their expectations inside a socio-educational field with rules and contents specific and distant from those observed in the country. This produces a tearing point in the scheme of expectations of the immigrants and increases tension between social agents. The analyses of this study show that the difference in expectations between the school and migrant families is related to the distance between the set of dispositions of each of them. This difference of expectations translates in different ways of conceiving participation and education. 
Table 5. Expectation gap between school and families.

\begin{tabular}{|c|c|c|}
\hline Expectation & From the School & From the Family \\
\hline $\begin{array}{l}\text { Participation in } \\
\text { educational activities. }\end{array}$ & $\begin{array}{l}\text { Participation limited by } \\
\text { quotas and depending on } \\
\text { specific activities. }\end{array}$ & $\begin{array}{l}\text { - Demands more spaces and opportunities for } \\
\text { participation in educational activities. } \\
\text { - Indifference regarding the existence of } \\
\text { larger spaces. }\end{array}$ \\
\hline $\begin{array}{l}\text { Relationship between school } \\
\text { and families. }\end{array}$ & $\begin{array}{l}\text { Precise relationship, related } \\
\text { information (highly formalized). }\end{array}$ & $\begin{array}{l}\text { - Aspiration integrated into the work of } \\
\text { the school. } \\
\text { - } \quad \text { They expect the fewest instances to meet. }\end{array}$ \\
\hline Goal of education. & $\begin{array}{l}\text { Transfer of contents and } \\
\text { discipline: pupils are expected } \\
\text { to be good students. }\end{array}$ & $\begin{array}{ll} & \text { Good education of students refers to: } \\
\text { - } & \text { Being a good person. } \\
\text { - } & \text { Future possible studies. } \\
\text { - } & \text { Children are well cared for. } \\
\end{array}$ \\
\hline Family educational support. & $\begin{array}{l}\text { Families must co-participate in } \\
\text { the process. }\end{array}$ & $\begin{array}{l}\text { - It is school's responsibility. } \\
\text { - } \quad \text { Also it is our duty. }\end{array}$ \\
\hline Future of the students. & $\begin{array}{l}\text { That students are well trained in } \\
\text { various subjects and can continue } \\
\text { studying (be professionals). }\end{array}$ & $\begin{array}{l}\text { - That they finish their education to } \\
\text { work soon. } \\
\text { - } \quad \text { That they be better than their parents. }\end{array}$ \\
\hline
\end{tabular}

\section{The Structuring of Symbolic Violence in the Educational Field: Assimilation and Domination}

This section discusses how symbolic violence is expressed through structured forms in the family-school relationship in the Chilean educational field. According to the observations, symbolic violence is structured in two main dimensions, namely structural rigidity and discriminating dispositions (see Table 6). In turn, each of these dimensions is categorized in different aspects, each of them codified and expressed in diverse manners. In the following table, these analytical distinctions are illustrated.

Table 6. Structuralization of symbolic violence.

\begin{tabular}{|c|c|c|c|}
\hline Dimension & Categorization & Code & Expression \\
\hline \multirow{3}{*}{ Structural rigidity } & \multirow{2}{*}{ Cultural assimilation } & Monolingualism & $\begin{array}{l}\text { - Predisposition of only one language } \\
\text { in the family-school relationship } \\
\text { (Spanish speakers). }\end{array}$ \\
\hline & & Homogenization & $\begin{array}{l}\text { - } \text { Generalization of traits of } \\
\text { the population. } \\
\text { - } \quad \text { Equality teaching strategies. }\end{array}$ \\
\hline & Regulatory rigidity & Imposition of the rules & $\begin{array}{l}\text { Families must conform to the rules } \\
\text { of the school. } \\
\text { - Lack of empathy for the situations } \\
\text { of families. } \\
\text { - Abuse and insults } \\
\text { toward families. }\end{array}$ \\
\hline $\begin{array}{l}\text { Discriminatory } \\
\text { provisions }\end{array}$ & Dynamics of domination & $\begin{array}{l}\text { Xenophobic and racist } \\
\text { dispositions from the } \\
\text { national families }\end{array}$ & $\begin{array}{l}\text { - Standardization and reproduction of } \\
\text { discriminatory practices. }\end{array}$ \\
\hline
\end{tabular}




\subsection{Structural Rigidity and Cultural Assimilation}

The way in which teaching in the school is performed acts as a cultural assimilation device [37]. This is explained by the dynamics of teaching, which tend to homogenize students and accentuate common features in order to increase the productivity of teaching. Thus, the closer the student is to the "profile" or "stereotype" to be taught, the more adequate the individual will be regarding the pedagogical strategies to be implemented. Namely, the school aims at having agents adequate for its practices.

Within this dimension, one observed form of symbolic violence occurs when the school applies a norm dictated from other agents enjoying a higher level in the hierarchical relationships of this field level. Such is the case of the educational policy of monolingualism. Language barriers were observed. These made the relationship between Spanish speakers and foreigners with a different mother tongue more complex. Neither the school nor the families who speak Spanish are proficient in a second language allowing them to communicate better. The prominence of the Spanish language in the educational field excluded and segregated families and students not proficient in it.

The set of rules and dispositions presented in the educational field promoted monolingualism. Therefore, a certain distance was developed between those fluent in the dominating language and those who were not, as observed in the next example:

"The communication with the Haitians parents is more difficult. They speak another language and I do it in Spanish. Then we put the kids between us for translation. Our communication has big difficulties. How I ask you to strengthen reading comprehension if the father does not speak Spanish? Then it is super complicated with parents who use another language. It is complicated..." [35].

As a consequence, the situation of students in a less advantaged position - in this case, foreign students - is a process that forces pupils to incorporate formal contents as dictated by the public institutions and that often fail to take care of what was part of the educational system of origin. This process, so demanding for the adaptation skills of foreign students, can be called a de-culturalization since it disregards the cultural resources acquired in their family and social class, and at the same time, it re-educates toward the cultural assimilation in linguistic terms.

\subsection{Normative Rigidity and the Imposition of Order}

Several examples illustrate the imposition of norms associated with the time and place in which the parents should or should not be at school. First, a feeling of insecurity regarding their children's protection is observed in the parents, since they are supposed to learn to blindly trust in those attending to their children.

"I think that the school needs to improve in this subject. Because when the children are standing in line, we must get out. They ring the bell and expel us outside, while the children stay there. I would like to stay there more time, to see, to know what is happening. It is very rigid." [38].

"It was like very suddenly. I was worried at first, the first day I was told to leave her at the school gate. I do not know, I felt worried.” [39]. 
The way in which teaching is carried out is sometimes misunderstood and worrisome to the parents, who must accept and adapt to measures imposed by the school. This type of example has a larger impact on immigrant families, who interact with the school with their "migrant stigma". This implies that significant hesitation precedes the communication of any complaint.

"As a parent asking the school to improve, is always more difficult, because I am a foreigner. They would say 'no, he is not from here and is asking for school improvement!' So better I stay silent.” [33].

On the other hand, from schools also have a view of themselves as social agents who must impose the norms of the social relationship with the families. This means that it must be optimal for families to adapt to the established rules. Otherwise, the school shall implement strategies strengthening its position. This is done in a subtle way, and is not recognized as such, but is rather seen merely as foreign families necessarily adapting. It is, thus, assumed that a teacher's work may legitimately reproduce such impositions.

"But why are you not integrated? This school permits to participate but only until one point, the school puts limits. It is ok, there are things for which it is necessary to put some limits, but not in the integration process. For example, do you know when are the parents invited to participate? For the international party...only then are we invited. And there are only a few who show up, why? Because they are almost always told 'no', and when you say 'no', they do not come again.” [40].

The school limits the families' participation. Although there are instances for the integration of families into a school's activities, limits are too rigid, announcements come too late and are not sent to everyone, and whenever parents propose something, this is not taken into account as the school has already planned everything. Families are just supposed to attend.

"Meetings is where dad and the school have to go to get along. Not because the parents always work, we have to be available to them. They also have to step into the shoes of the school, where there are schedules and protocols to follow. We cannot do that on Monday at 7 p.m., to meet with the fifth grade, because regulation does not permit it." [41].

The abovementioned point is also perceived by some Chilean parents, who observe normative rigidity and violence both toward themselves and the students. The school does not seem to empathize with those parents lacking time to attend meetings. Therefore, the timing at disposal for schools is not in tandem with that of the parents. For instance, the proposed time for a meeting does not often suit parents, and if they arrive late, they may not be received.

"The other day, the supervisor called a mom to speak at 8 a.m., and the lady has two children who are in school, plus another little girl and a baby. She arrived a little late and said, 'I had to prepare the girl and the baby to come out, I cannot leave them alone', she had to come with both and it was winter. The supervisor said, 'No, I asked her to come to a specific time and did not attend her because she should have arrived at the time he had booked.' He is rigid, and in that regard I find that should not be the way in a supervisor." [42]. 
In addition, the structuralization of symbolic violence in the interaction between families and the school was observed. School is envisioned as a social agent working along rigid norms, which symbolically infringe those under them. These norms do not totally empathize with families, who have a disadvantage whenever they want to exercise their rights.

However, it is worth noting that there are agents who speak out their worries regarding the occurrence/reproduction of discrimination and stigmatization toward the people coming from abroad. They demand from the school and the broader school community a bigger acknowledgement of the socio-cultural diversity of their students, in order to foster respect and tolerance.

"That has to do with respect, dignity, tolerance. It seems to me very important also to be competent regarding knowledge. This is, I have heard professionals say 'black of the jungle' and fight because he is black and comes from the jungle. As far as I know, Colombia has more than just jungle. It also has asphalt, has cities, has democratic institutions, etc. So, I see a lack of important knowledge. Skills related to managing diversity." [43].

In the example, a denaturation of dispositions that reproduces processes of symbolic violence was witnessed. An alternative lies in the education of the same agents comprising the school.

In summary, the analysis shows that the Chilean school system is a highly institutionalized social field in which the social action rules are arbitrarily produced by the agents who dominate this field, and they can be regarded as the core of the symbolic violence emerging in the educational centers. The structuralization of the educational field is rigid and highly formal, producing exclusion and segregation of foreigners. At the same time, this has an impact on the relationships among the social agents subject to the norms of the school.

\subsection{Discriminatory Disposition from Some Social Agents: Domination Dynamics}

In the previous section, it was exhibited how, in the social educational field, there exist domination relationships incorporated into its structure. Hence, in the educational field, the school is an agent exerting naturalized dominating dynamics. This has an impact on the way differences are categorized. This is presented as an incentive to perceive and evaluate migrants (tall/short, white/black, etc.), thus establishing categorizations that become natural as distinctions in the social reality, in which the foreigner is categorized as an other, who is a victim of xenophobic and racist dispositions.

"Do you have relationships with immigrant families? No, I greet them only. But very little. Greeting, nothing else, but if they ask me something, I answer.” [44].

"Why do I dislike Peruvians? I do not like them, do not like them. What do you dislike? They walk smelly. I do not like the smell, it's just smells like spices. I do not like it. I really hate to say it, but I do not like it. Is that...I cannot explain it well but I do not like it. I do not like the smell of them, I do not like how they hang out." [45].

"Have you ever had a Peruvian friend? I talk to two, but we are not friends, but we talked. But I reject them. I do not know why, really do not know if they have never done anything to me. I have never ever had a problem with a Peruvian. Never, but I do not know why I do not like and do not like them. I do not like them." [45]. 
In this scenario, it is possible to maintain that the forms of discrimination-bullying, racism, xenophobia, etc.- - are expressions of symbolic violence and negative dispositions toward cultural differences. There are some families who deny migrant families the status as full interlocutors in social interactions, as a consequence of the incorporation of xenophobic patterns of social valuation.

According to observations, the social educational field can be considered as a space where the struggle among social agents provokes conflicts of varying magnitude. The school was presented as an agent that welcomes both migrant families and otherwise. This situation may have paradoxical affects, albeit it promotes social integration, it may generate certain exclusion mechanisms, since trying to integrate everyone in the same way provokes violent interactions between families.

"The school from the beginning welcomed us, but there are others who are sometimes a little distant because you come from abroad. Because sometimes here Chileans are a little bit racist. When you approach them for something, or want to make a query, they ignore you" [32].

In this dimension it is worth noting that the violence context is not solely restricted to the migrant population, but it is inscribed in a context of generalized violence in which the relationships between families take part.

"I was treasurer in prekindergarten and this mom told me, 'I am going to stab if you to charge money.' And I told her that the money is for the participation of her daughter in the cerebration at the end of the year. She says me, 'You will see.' So they are very aggressive. These are Chilean parents. Migrants do not, they are good, quietly, speak the minimum.” [44].

In the same fashion, migrant families find themselves in a disadvantaged position with respect to national families and the school. Migrant families have difficulties to obtain explicit and practical recognition from local ones. This is related to their relatively lower level of symbolic capital. Symbolic violence, expressed as racism and xenophobia, is reproduced inter-generationally. Many of the interviewed agents notice that children and their parents have incorporated an unconscious rejection of foreigners; they have normalized the discrimination of the cultural difference. This phenomenon is recognizable everywhere from schoolteachers to migrant parents.

"It made me wonder the attitude of the national children regarding foreign class mates. There is a racist attitude in the children. I think it should be family learnt. So, I do not know what the relationships among adults with migrants is. Because in reality children are a reflection of home. Sometimes you see attitudes very, very racist, xenophobic ones...it is striking. What they are hearing about it at home?" [46].

In the same way, it has been observed that the children have incorporated an imagery regarding the foreigner, and with it they have normalized verbal abuse, such as cursing, toward them. National families and their offspring position themselves naturally in a higher hierarchy than foreigners, which in connection to the dominating culture assigns them a higher symbolic capital in the school. In this sense, the unequal dispositions of symbolic capital have even affected the relationships between local and foreign students. 
"We had problems because in the first year they discriminated against my son, there was a bit of discrimination." [47].

"In the early days, they cut his hair, peers, in the first year. Actually they are girls, they feel they are more valuable...the first day they broke his apron. Looks like being torn, whatever. But I found my son crying." [48].

Again, it is worth mentioning that it is not possible to generalize the idea that all national families have a negative disposition toward differences. Rather, it is possible to identify ideas in the social agents pointing toward educating the children in a way that assimilates diversity without discriminating or expressing negative feelings toward foreigners.

"My daughter once used the word black. I said, 'No, that is an ugly word' because it is discriminating, people are brunettes, they are well tanned, but not black because it is ugly. I think it is a derogatory word. Then my daughter usually says 'brown people'. I care for diversity of color, they are human beings as us, but the difference is in skin or hair. And the vast majority of black women use extensions because the hair is different, weird, I do not know. There is a little boy who has to go to kindergarten, his hair is curly...but not bad, but it strikes me, the diversity." [49].

Nevertheless, despite the existence of some local families having no negative feelings toward diversity, it is important that this form of teaching be assumed as a shared strategy between the families and the school, in which the latter must take on a mediating role between tense relationships. Observing the interaction between immigrant and national families, Touriñán [50] remarks that, in the educational system, the school becomes a co-habitation space for the immigrant and the national, where the dynamics of meeting and learning to accept each other are produced, and they are not exempt from problems, such as verbal, and sometimes, physical violence. Acknowledging that this process carries conflicts, the school is envisioned as playing a fundamental role in the generation of values associated with the respect of the foreigner and the rejection of discriminating practices [37].

"Sometimes some answer no, they are not from here and come to impose their laws on us. Here sometimes, I observed people with that attitude, but do not say it directly. And these parents are Chilean? Yes, they are Chileans, of course. Well, in the end it is the teacher who sometimes takes the word and explains to the people. The teacher is the one who seeks consensus." [51].

In summary, symbolic domination dynamics caused by structural rigidities (school-family) are observed, and these are not isolated from the structures of violence influenced by the dispositions of some social agents that participate in them. This is to say that the context shows a double form of symbolic violence, which is part of the dynamics in the field.

\section{Conclusions}

The purpose of this article was to analyze, from a Bourdieuninan perspective, the conflict between family and school in the context of a high immigrant population. The analysis performed in this article made it possible to identify, in the cases being studied, a conflict produced by capital diversity, 
different expectations, dispositions, and practices among the social agents. Migration in Chile has become an enduring process, bringing various difficulties in the general functioning of the social services. Social fields, such as health and education, have experienced a series of complications in serving the migrant/national population. Beyond the problems related to serving an increasing demand, there is an emergency of conflicts among users and between these and the institutions providing services. On top of this setting, the conflict in the family-school relationship within the Chilean educational field was analyzed. In particular, we focused on the discrepancy of interests and expectations between the agents and the correlated forms of symbolic violence operating in these relationships.

Concerning the specific objective of characterizing the main difficulties immigrant families faced during their experience in the socio-educative realm, we found differences in volume and in the structuration of the capital among the different agents being studied. The family groups possessed different levels of capital, impacting their relationships with the school. Generally, they had a low economic capital, expressed in unstable low-skill jobs and salaries. Families have relatively stable social relationships and support networks; however, migrant family groups have lost contact with their original support network and have trouble in kick-starting relationships with their neighbors and the school community, reducing the possibilities of care for their offspring. In other words, the social capital is high in families that have spent several years living in the same place and is reduced for families coming from abroad.

Beyond observing different levels of economic and social capital, the most differentiating aspect is the difference in cultural capital between the families. A high cultural capital institutionalized and referred exclusively to the level of schooling makes a good support for the educational process of the children; inversely, a low level of this kind of capital negatively affects the possibilities of school support of the families toward their children.

Along these lines, it was observed that through cultural capital the families generate different dispositions that have an influence on the expectations with respect to education and in the value assigned to schools. Three types of dispositions were observed. One type exhibits a positive valuation of education for the future of the children and highlights the educating role of schools. Another type disregards the connection between education and the future of the children, and only sees school as a place for protection and security for them. The third type asserts a neutrality of sorts: on a discursive level, education is given an important character, yet in practice, nothing is done to support the learning process. Here, school is merely a place for children to be while the parents work. It is highlighted that school is regarded as an expert agent in the transmission of cultural capital to the students, but it also must embrace its duty to confront the disposition the families have, which is clearly a complex task and not free of conflicts itself.

In relation to the specific objective to define the facets of the conflict between family and school, in order to understand the observed family-school conflict, it is important to consider the concept of habitus as introduced by Pierre Bourdieu. In the family-school conflict it was noticed that schools dealing with intercultural dynamics try to broaden the reference points between nationals and immigrants; however, the lack of communication and low empathy observed in the relationship facilitates the configuration of a conflict whose core is the juxtaposition of the habitus among the different agents belonging to the school community. 
Regarding the problem of the symbolic structures operating in the interaction between the agents, it was remarked that the conflict between the migrant families and the schools is related to three fundamental aspects: the clash of interests, the divergence of expectations, and the different dispositions toward actions between the agents. The clash of interests refers to the differences in the valuation of education and the educational space. This has to do with the role that the agents assign to the school. For some families, the school is specifically a teaching being, whereas for others, it is a place for the protection of the children while they work. This is linked to the diversity of accompanying practices for the families in the formative process. The existence of families helpful in the educational process of the children, since they value education as a social mobility factor, was observed. On the other hand, a low valuation of the educational process does not promote supporting or assisting practices in the academic tasks of their offspring.

In turn, the differing dispositions relate to the practical sense/interpretation of the educational field. This is linked to the different predispositions shown by the families in the social-educational field as a result of their past experiences. The history of the family-school relationship is important in the present state of it. Positive experiences based on good service and teaching favor adaptation in schools and foster high expectations regarding the educational process. Opposite to this, negative experiences likewise influence the upbringing of the children, the adaptation of the families into schools, and neutralize or reduce the quality of the agents' expectations.

In relation to the last specific objective, to explore the presence of symbolic violence in this relationship, it was noted that a different angle of conflict is given to the disregard of social diversity. This implies symbolic violence in view of Bourdieu, due to the supremacy of norms and field rules not necessarily coherent with the variety of pre-constructed expectations of the families, both immigrant and local ones. Symbolic violence is structured based on two main dimensions: the structural rigidity promoted by the school, and the agents' discriminating dispositions.

The first one refers to the assimilationist logic with which schools work and has to do with the monolingualism and homogenization with which both national and foreign students are confronted. Likewise, a high degree of normative rigidity is observed, related to the imposition of specific rules by the school that limit the action scope and force families to abide to the institutionalized dispositions. Many of these norms are implicit and are normalized as day-to-day practices that often involve physical and verbal abuse toward the students or the omission of the family or work-related circumstances of the parents.

The second one, the discriminating dispositions, have to do with symbolic domination dynamics adjacent to xenophobic or racist dispositions in the national population, which deny or oppose the cultural diversity present in schools.

In view of the analysis undertaken, the social relationships between the agents appear determined by their dispositions. The practical sense agents present to participate in the educational field is structured according to their ways of thinking, feeling, and acting, and these stem from a cultural base that propels individuals, groups, and institutions apart. According to this, the conflict between the school and the families alludes to the distinction of the dispositions in the educational field, which, in the emerging integration process, generate convergences and divergences, power struggles, and conflicts of multiple meaning and complexity. Concretely, agents' different ways of thinking and acting generate a 
tension between the families' habitus, their expectations, and those of the school in the setting of the rules present in the educational field.

The results show that, in Chile, the school system that delivers education in a context of cultural diversity is not an appropriate model of social integration. It makes diversity invisible, and wastes the previous learning processes that students and families have. Faced by this, it is recommended to stand from a perspective that sees differences as a human feature and therefore understands them as "natural".

This implies taking into account families' expectations and, from there, generating strategies fostering intercultural understanding. On the other hand, immigrant families must use their operative capital to become visible as valid agents and interlocutors toward the school and the other actors in the social field.

Hence, by means of making flexible the relationships between the agents of this social field, along the lines of acknowledging strategies, progress toward a greater social justice is made. This implies that the family should be considered as a fundamental agent in the transmission of support and school valuation because agents produce forms of perception from what they learn from family interactions, and this gets translated into action within different social fields.

All this being said, a challenge, associated with schools' re-construction as a place of meeting for intercultural relationships, is identified. Since this is a platform of transformation of social imageries and acquisition of capitals (symbolic, social, and cultural), it has an impact even in the insertion of agents into other social fields, such as labor, and yields marked differences in the life quality of said agents.

This results especially true for migrants, who are more vulnerable, as they are immersed in a process of social integration in which many of them have a lower volume of capital than locals-fewer networks and links, lower wages, etc. - that operate as a helping device for their insertion in the host country.

In summary, the differences in the symbolic structures and the expectations of the agents, such as national or international families and schools, influence the configuration of conflict in the socio-educational field in Chile. However, there are also other symbolic structures influencing the conflict, which are associated with control mechanisms, educational road-maps, and forms of operation determined by the state as an agent that shapes the educational field. These context-dependent dimensions, which complicate the conflict further, will be investigated in a forthcoming paper.

\section{Acknowledgments}

I would like to thank the reviewers and editors for their constructive comments which vastly improved this article, as well as to "Understanding and Supporting Families with Complex Needs" for giving me the possibility to participate it. Finally, I thank Julio Daniel Backhoff Veraguas for his aid in translating this article.

\section{Author Contributions}

This article contains partial results from the research project "On the family-high school relationship as instrumental codependency in a context of high immigrant population: provisions and strategies for participation and educational support" undertook by Rayen Cornejo Torres in the framework of the project "Understanding and Supporting Families with Complex Need". Therefore the subject, research problem and fieldwork correspond to a study conducted personally by the author. Ariel Rosales Ubeda collaborated in the overall writing and in the discussion of the article. 


\section{Conflicts of Interest}

The authors declare no conflict of interest.

\section{References and Notes}

1. World Bank. "Datos sobre migración y remesas, Segunda edición." Available online: http://siteresources.worldbank.org/INTPROSPECTS/Resources/334934-1110315015165/Factbook 2011Spanish.pdf (accessed on 3 September 2015).

2. Organización internacional de migración (OIM). "Informe sobre las migraciones en el mundo 2011: Comunicar eficazmente sobre la migración." Available online: http://publications.iom.int/ bookstore/free/WMR2011_Spanish.pdf (accessed on 3 September 2015).

3. CEPAL. "Taller sobre evaluación y estimaciones demográficas con información censal. Medición y análisis de la migración internacional según los censos, las potencialidades del Proyecto IMILA y otras fuentes.” 2012. Available online: http://www.cepal.org/celade/noticias/paginas/9/51449/ jm_migracioninternacional.pdf (accessed on 3 September 2015)

4. Stefoni, Carolina. "Perfil migratorio de chile." 2011. Available online: http://priem.cl/wp-content/ uploads/2015/04/Stefoni_Perfil-Migratorio-de-Chile.pdf (accessed on 8 May 2015).

5. Bourdieu, Pierre, and Jean-Claude Passeron. La Reproducción. Elementos para una teoría del Sistema de Enseñanza. Mexico City: Distribuciones Fontamara, 1996.

6. Odina, María Teresa Aguado, Inés Gil-Jaurena, and Patricia Mata Benito. Educación Intercultural: Una Propuesta Para la Transformación de la Escuela. Madrid: Ediciones Catarata, 2005.

7. Stefoni, Carolina, Elaine Acosta, Marcia Gaymer, and Francisca Casas-Cordero. Niños y Niñas Inmigrantes en Santiago de Chile. Entre la Integración y la Exclusión. Santiago: Organización Internacional para las Migraciones, Universidad Alberto Hurtado, 2008.

8. Villalobos, Christopher, and Claudia Carrillo. "Inclusión/exclusión de estudiantes inmigrantes en Chile. La emergencia de un fenómeno sociocultural en el sistema educativo chileno." Paper presented at I Bienal Latinoamericana de Infancia, Manizales, Colombia, 17-21 November 2014.

9. Departamento de Extranjería y Migraciones (DEM). "Informe Anual Sección Estudios. Gobierno de Chile.” 2010. Available online: http://www.extranjeria.gob.cl/filesapp/Informe\%20Estimacion\% 20Poblacion\%20Extranjeros\%202008.pdf (accessed on 8 March 2011).

10. Pizarro, Jorge Martínez. El encanto de los datos. Sociodemografía de la inmigración en Chile según censo 2002. Santiago: CEPAL/CELADE, 2003, vol. 49.

11. CEPAL/CELADE. "Migración Internacional." 2006. Available online: http://www.cepal.org/ es/temas/migracion-internacional (accessed on 3 September 2015).

12. Doña Reveco, Cristian. "Transnacionalismo y nuevas perspectivas de integración.” Paper presented at Primer Coloquio Internacional, Zacatecas, México, 23-25 October 2003.

13. Hein, Kerstin. Migración y Transición: Hijos de Inmigrantes de Origen Latinoamericano en su Transición de la Escuela al Trabajo en Chile. Santiago: Revista Si Somos Americanos, 2012, vol. 12.

14. Mora, Claudia. “Globalización, Género y Migraciones.” Revista Polis 7 (2008): 285-97.

15. Tijoux-Merino, María Emilia. "Niños y niñas de la inmigración y búsqueda de la reflexividad para enfrentar su discriminación.” 2014. Available online: http://www.junji.cl/SiteAssets/JUNJI/ 
documentos/2014/seminario_infancia_e_inmigracion/Tijoux_seminario_JUNJI.pdf (accessed on 8 May 2015).

16. Stefoni, Carolina. "Inmigrantes en Chile. Una integración diferenciada al mercado laboral." In Migración y Políticas Sociales en América Latina. Sopla: Konrad Adenauer Stiftung, 2008.

17. Bourdieu, Pierre. Meditaciones Pascalianas. Barcelona: Anagrama, 1997.

18. Flick, Uwe. Introducción a la Investigación Cualitativa. Edited by Ediciones Morata. Madrid: Fundación Paideia Galiza, 2004.

19. Bourdieu, Pierre. Las Estrategias de la Reproducción Social. Buenos Aires: Siglo Veintiuno Editores, 2011.

20. Bourdieu, Pierre. "The forms of capital." In Handbook of Theory and Research for the Sociology of Education. Edited by John G. Richardson. New York: Greenwood Publishing Group, 1983.

21. Bourdieu, Pierre. La Distinción. Buenos Aires: Alfaguara Ediciones, 2012.

22. Bourdieu, Pierre. El Sentido Práctico. Madrid: Editorial Siglo XXI, 2007.

23. Virginia Braun, and Victoria Clarke. "Using thematic analysis in psychology." Qualitative Research in Psychology 3 (2006): 77-101. Available online: http://dx.doi.org/10.1191/14780887 06qp063oa (accessed on 8 May 2015).

24. Tovillas, Pablo. Bourdieu: Una introducción. Buenos Aires: Queadrata, 2010.

25. Henríquez, Andrés Aedo. "El habitus y la movilidad social: De la modificación del sistema de disposiciones a la transformación de la estructura de clases.” Revista de Sociología 29 (2014): 57-75.

26. O'Reilly, Karen. International Migration and Social Theory. Houndmills: Palgrave MacMillan, 2012.

27. Pintor Sandoval, Renato. "El habitus y los Campos Transnacionales en el Proceso del Transnacionalismo Migrante." Migraciones Internacionales 6 (2011): 159.

28. Lareau, Annette. Unequal Childhoods. Class, Race, and Family Life, with Update a Decade Later. Berkeley, Los Angeles and London: University of California Press, 2011.

29. Interviewee 1 (school team, Santiago, RM, Chile). Interview 9, 2013.

30. Interviewee 2 (school team, Santiago, RM, Chile). Interview 8, 2013.

31. Interviewee 3 (immigrant parent, Santiago, RM, Chile). Interview 2, 2013.

32. Interviewee 4 (immigrant parent, Santiago, RM, Chile). Interview 12, 2013.

33. Interviewee 5 (immigrant parent, Santiago, RM, Chile). Interview 22, 2013.

34. Interviewee 6 (school team, Santiago, RM, Chile). Interview 20, 2013.

35. Interviewee 7 (school team, Santiago, RM, Chile). Interview 7, 2013.

36. Interviewee 8 (school team, Santiago, RM, Chile). Interview 17, 2013.

37. Alarcón Muñoz, Gonzalo Esteban. "Las Políticas Inmigratorias De Chile En El Área Educativa. El Caso De Los Peruanos En Chile." Master Thesis, University of Chile, Santiago, Chile, March 2010.

38. Interviewee 9 (immigrant parent, Santiago, RM, Chile). Interview 3, 2013.

39. Interviewee 10 (immigrant parent, Santiago, RM, Chile). Interview 24, 2013

40. Interviewee 11 (immigrant parent, Santiago, RM, Chile). Interview 5, 2013.

41. Interviewee 12 (school team, Santiago, RM, Chile). Interview 11, 2013.

42. Interviewee 13 (national parent, Santiago, RM, Chile). Interview 6, 2013.

43. Interviewee 14 (school team, Santiago, RM, Chile). Interview 28, 2013.

44. Interviewee 15 (national parent, Santiago, RM, Chile). Interview 1, 2013.

45. Interviewee 16 (national parent, Santiago, RM, Chile). Interview 15, 2013. 
46. Interviewee 17 (school team, Santiago, RM, Chile). Interview 18, 2013.

47. Interviewee 18 (immigrant parent, Santiago, RM, Chile). Interview 27, 2013.

48. Interviewee 19 (immigrant parent, Santiago, RM, Chile). Interview 32, 2013.

49. Interviewee 20 (national parent, Santiago, RM, Chile). Interview 29, 2013

50. Touriñán-López, José M. "La educación intercultural como ejercicio de educación en valores." Estudio Sobre Educación 10 (2006): 9-36.

51. Interviewee 21 (immigrant parent, Santiago, RM, Chile). Interview 21, 2013.

(C) 2015 by the authors; licensee MDPI, Basel, Switzerland. This article is an open access article distributed under the terms and conditions of the Creative Commons Attribution license (http://creativecommons.org/licenses/by/4.0/). 